Check for updates

Cite this: RSC Adv., 2017, 7, 22409

\title{
Control of ATP concentration in Escherichia coli using an ATP-sensing riboswitch for enhanced S- adenosylmethionine production
}

\begin{abstract}
Yawei Chen, (D) *a Huiyun Zhou, ${ }^{a}$ Meng Wang ${ }^{\mathrm{b}}$ and Tianwei Tan*b
ATP is the limiting precursor for S-adenosylmethionine (SAM) synthesis in Escherichia coli. In contrast to traditional optimization of fermentation processes, the riboswitch-based strategy, which was developed as a novel efficient regulation approach, has been applied for the control of the intracellular ATP concentration in order to promote the production of SAM. In this work, a newly discovered ATP-sensing riboswitch $y d a O$ motif was used to balance the requirement of ATP in SAM biosynthesis. The results show that the RNA element $y d a O$ from Bacillus subtilis could play a role in regulating gene expression in E. coli. The $y d a O$ motif-based regulation strategy, which was induced by ATP, improved the ATP level as well as the titer of SAM. The intracellular SAM titer of the best-performing strain, AYV, produced the highest SAM titer ( $1.23 \mathrm{mg} \mathrm{L}^{-1}$ ) which was increased by about $55 \%$ compared with the control. Overall, the method enabled new insights into the regulation of ATP in E. coli. These results demonstrate a strategy for optimally employing an ATP-sensing riboswitch for the ATP balance of industrial ATPdriven bioprocesses.
\end{abstract}

Received 1st March 2017

Accepted 16th April 2017

DOI: $10.1039 / \mathrm{c} 7 \mathrm{ra02538f}$

rsc.li/rsc-advances

Increased concentration of ATP would enhance SAM

\section{Introduction}

S-Adenosylmethionine (SAM) is a key active compound in many biological reactions of living organisms and serves as a major donor in many metabolic pathways, such as transmethylation, transsulfuration and aminopropylation. ${ }^{1-4}$ SAM has shown great clinical potential as a chemotherapeutic agent in various diseases, including arthritis, ${ }^{5}$ liver disease ${ }^{6,7}$ and depression. ${ }^{\mathbf{8}, 9}$ Accordingly, several attempts have been made to improve SAM production. ${ }^{10}$ Compared with enzyme catalysis and chemical synthesis, fermentation using yeast to produce SAM is more advantageous for industrial applications.

Generally, SAM is synthesized from L-methionine and ATP under the catalysis of methionine adenosyltransferase in living organisms. L-Methionine as the limiting precursor in the SAM biosynthesis is usually added directly to the medium as a supplement in the fermentation process. ${ }^{\mathbf{1 1 - 1 4}}$ However, intracellular ATP as a precursor and energy carrier is also a main limiting factor for SAM production. As ATP is difficult to manipulate in the same simple way, optimization of the fermentation process is an alternative option to enhance ATP supply. ${ }^{\mathbf{1 5 , 1 6}}$ But beyond that, there is a lack of reliable and efficient methods for ATP regulation.

${ }^{a}$ College of Chemical and Pharmaceutical Engineering, Henan University of Science and Technology, 263 Kaiyuan Avenue, Luoyang 471023, PR China. E-mail: yaweichen@aliyun.com; Tel: +8637964231914

${ }^{b}$ National Energy R\&D Center for Biorefinery, College of Life Science and Technology, Beijing University of Chemical Technology, Beijing 100029, PR China production whereas excessive levels of ATP can inhibit cell growth. ${ }^{17}$ We have weakened specific metabolic pathways of byproducts by a synthetic sRNA-based regulation strategy to control the intracellular ATP level in previous study. ${ }^{18}$ However, the regulation of this strategy is limited, because it can only upregulate or down-regulate the intracellular ATP level. The development of riboswitch has offered a novel approach utilizing a ATP-sensing riboswitch to regulate the intracellular ATP level dynamically. ${ }^{19,20}$ To the best of our knowledge, a riboswitch-based strategy has not previously been used for the regulation of ATP in metabolites biosynthesis.

The $y d a \mathrm{O}$ motif is a kind of natural RNA which can specifically bound ATP molecular and regulate expression of endogenous genes in response to ATP concentrations in Bacillus subtilis. ${ }^{19}$ The $y d a \mathrm{O}$ motif as other all known riboswitches acts within feedback loops, modulating expression of specific enzymes in response to on-pathway metabolites. When the intracellular ATP concentration is higher than a certain level, the $y d a \mathrm{O}$ motif and the ATP molecules form a stem loop structure of RNA which hinders the transcription of the certain gene downstream of $y d a \mathrm{O}$. On the contrary, when the intracellular ATP concentration is lower, ydaO motif itself can act as a transcriptional promoter element on downstream genes. Therefore, the rational use of ATP sensing riboswitch ydaO motif will be possible to achieve the dynamic control of ATP concentration at a certain level, which is most beneficial to the synthesis of intracellular ATP dependent products (Fig. 1). 


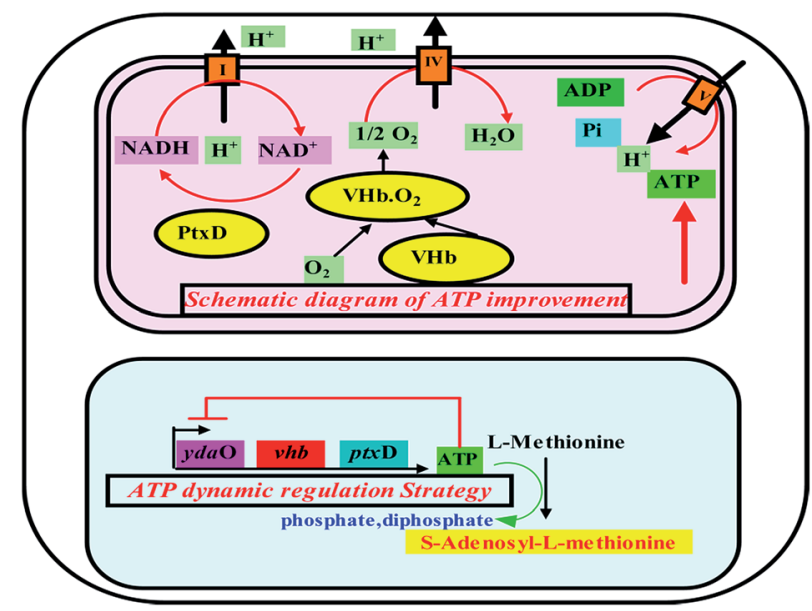

Fig. 1 Schematic diagram of ATP improvement by $v h b$ and $p t x \mathrm{D}$ and dynamic regulation strategy using ydaO motif in $E$. coli ydaO: a kind of riboswitch which can specifically bound ATP molecular and regulate expression of endogenous genes in response to ATP concentration; $v h b$ : encoding Vitreoscilla hemoglobin $\mathrm{VHb}$ that could bind oxygen, particularly under low $\mathrm{O}_{2}$ conditions, and deliver it to the respiratory chain by direct interaction with the terminal respiratory cytochrome; ptxD: encoding phosphite dehydrogenase PTDH that could catalyze the nearly irreversible oxidation of phosphite to phosphate, with the concomitant reduction of $\mathrm{NAD}^{+}$to $\mathrm{NADH}$.

Here, we proposed an ATP-sensing riboswitch-based strategy which could be applied to regulate the intracellular ATP concentration in E. coli. The effects of strategy on the SAM production and energy metabolism were investigated.

\section{Materials and methods}

\section{Strains, plasmids and growth conditions}

The $E$. coli strains were cultivated in Luria-Bertani (LB) medium ( $1 \%$ tryptone, $0.5 \%$ yeast extract, $1 \% \mathrm{NaCl}$ ) supplemented with appropriate antibiotics. Overnight cell culture $(1 \%, \mathrm{v} / \mathrm{v})$ was inoculated into $100 \mathrm{~mL}$ M9 mineral medium containing $100 \mu \mathrm{g}$ $\mathrm{mL}^{-1}$ kanamycin or ampicillin. A defined M9 medium (per liter) contained glucose $20 \mathrm{~g}, \mathrm{Na}_{2} \mathrm{HPO}_{4} \cdot 2 \mathrm{H}_{2} \mathrm{O} 7.52 \mathrm{~g}, \mathrm{KH}_{2} \mathrm{PO}_{4} 3 \mathrm{~g}$, $\mathrm{NaCl} 0.5 \mathrm{~g}, \mathrm{NH}_{4} \mathrm{Cl} 0.5 \mathrm{~g}, \mathrm{MgSO}_{4} \cdot 2 \mathrm{H}_{2} \mathrm{O} 0.25 \mathrm{~g}, \mathrm{CaCl}_{2} \cdot 2 \mathrm{H}_{2} \mathrm{O}$ $0.15 \mathrm{~g}$, biotin $1 \mathrm{~g}$, thiamin-HCl $1 \mathrm{~g}$ and $10 \mathrm{~mL} 100 \times$ trace elements solution. The $100 \times$ trace elements solution (per liter) contained EDTA $5 \mathrm{~g}, \mathrm{FeCl}_{3} \cdot 6 \mathrm{H}_{2} \mathrm{O} 0.83 \mathrm{~g}, \mathrm{ZnCl}_{2} 84 \mathrm{mg}, \mathrm{CuCl}_{2}$ $\cdot 2 \mathrm{H}_{2} \mathrm{O} 13 \mathrm{mg}, \mathrm{CoCl}_{2} \cdot 2 \mathrm{H}_{2} \mathrm{O} 10 \mathrm{mg}, \mathrm{H}_{3} \mathrm{BO}_{3} 10 \mathrm{mg}, \mathrm{MnCl}_{2} \cdot 4 \mathrm{H}_{2} \mathrm{O}$ $1.6 \mathrm{mg}$. Triple experiments were carried out.

\section{Plasmid construction}

E. coli Top 10 was used for plasmid cloning and maintenance. $E$. coli BL21 (DE3) was used as parent strain for the SAM production. The strains and plasmids used in this study are listed in Table 1. All primers used in this study are listed in Table 2. The schematic overview of the plasmids design and construction are shown in Fig. 2. The ydaO motif was amplified from chromosomal DNA of strain Bacillus subtilis with primers Xba I-ydaO-F and $B a m H \mathrm{I}-y d a \mathrm{O}-\mathrm{R}$. The DNA fragment was digested with $X b a \mathrm{I}$ and $B a m H$ I, and cloned into the vector pRSFDuet-1. The EGFP
Table 1 Strains and plasmids in this study

\begin{tabular}{|c|c|c|}
\hline Strains & Description & Source \\
\hline E. coli $\mathrm{TOP} 10$ & Cloning host & Biomed \\
\hline E. coli $\mathrm{BL} 21$ (DE3) & Expression host & Biomed \\
\hline Control Y & $\begin{array}{l}\text { E. coli BL21 harboring } \\
\text { pRSFDuet- } y d a \mathrm{O}\end{array}$ & This study \\
\hline Control G & $\begin{array}{l}E \text {. coli BL21 harboring } \\
\text { pRSFDuet-EGFP }\end{array}$ & This study \\
\hline AYG & $\begin{array}{l}\text { E. coli BL21 harboring } \\
\text { pRSFDuet-ydaO-EGFP }\end{array}$ & This study \\
\hline AYV & $\begin{array}{l}\text { E. coli BL21 harboring } \\
\text { pRSFDuet-ydaO-vhb }\end{array}$ & This study \\
\hline AYP & $\begin{array}{l}\text { E. coli BL21 harboring } \\
\text { pRSFDuet-ydaO-ptxD }\end{array}$ & This study \\
\hline \multicolumn{3}{|l|}{ Plasmids } \\
\hline pET28a-EGFP & Harboring $E G F P$ & Lab collection \\
\hline pUC57-ptxD & $\begin{array}{l}\text { Amp }^{\mathrm{R}} \text {, synthetic gene } \\
\text { ptx } \mathrm{D}, \\
\text { optimized in } S . \\
\text { cerevisiae codon }\end{array}$ & Lab collection \\
\hline pUCK-vhb & $\begin{array}{l}\text { Amp }{ }^{\mathrm{R}} \text {, synthetic gene } \\
v h b\end{array}$ & Sangon biotech \\
\hline pRSFDuet-ydaO & Harboring $y d a \mathrm{O}$ & This study \\
\hline pRSFDuet-EGFP & Harboring $E G F P$ & This study \\
\hline pRSFDuet- $y d a \mathrm{O}-E G F P$ & $\begin{array}{l}\text { Harboring } y d a \mathrm{O} \text { and } \\
E G F P\end{array}$ & This study \\
\hline pRSFDuet-ydaO-v $h b$ & $\begin{array}{l}v h b \text { gene in pRSFDuet- } \\
y d a \mathrm{O}\end{array}$ & This study \\
\hline pRSFDuet- $y d a \mathrm{O}-p t x \mathrm{D}$ & $\begin{array}{l}p t x \mathrm{D} \text { gene in pRSFDuet- } \\
y d a \mathrm{O}\end{array}$ & This study \\
\hline
\end{tabular}

fragment was obtained by PCR with primers BamH I-EGFP-F and $X$ ho I-EGFP-R using plasmid pET28a-EGFP as a template. The constructed plasmid pRSFDuet-ydaO and the EGFP fragment were both digested with BamH I and Xho I, and designated as pRSFDuet-ydaO-EGFP.

Table 2 Primers used for PCR in this study ${ }^{a}$

\begin{tabular}{|c|c|c|}
\hline Constructs & Oligo name & Oligonucleotides $\left(5^{\prime}-3\right)$ \\
\hline \multirow[t]{2}{*}{$y d a \mathrm{O}$} & $X b a$ I-ydaO-F & TACTCTAGAGATTTTAGCCTCTG \\
\hline & BamH I-ydaO-R & GATGGATCCAATCAAAAAACGTTTGA \\
\hline \multirow[t]{2}{*}{$E G F P$} & BamH I-EGFP-F & $\begin{array}{l}\text { ATTGGATCCATCGCCACCATG } \\
\text { GTGAG }\end{array}$ \\
\hline & Xho I-EGFP-R & $\begin{array}{l}\text { GTGCTCGAGTGCGGCCGCTTTA } \\
\text { CTTGTAC }\end{array}$ \\
\hline \multirow[t]{2}{*}{$p t x \mathrm{D}$} & BamH I-ptxD-F & $\begin{array}{l}\text { CGGGATCCATGCTGCCTAAAC } \\
\text { TGGTCATCA }\end{array}$ \\
\hline & Xho I-ptxD-R & $\begin{array}{l}C C G C T C G A G T T A G C A C G C C G C A G \\
\text { GTTCCGCTTT }\end{array}$ \\
\hline \multirow[t]{2}{*}{$V h b$} & BamH I-vhb-F & $\begin{array}{l}\text { CGGGATCCATGTTAGACCAGCAA } \\
\text { ACCATTAACA }\end{array}$ \\
\hline & Xho I-vhb-R & $\begin{array}{l}\text { CCGCTCGAGTTATTCAACCGC } \\
\text { TTGAGCGT }\end{array}$ \\
\hline qPCR & $\mathrm{qgapdh}-\mathrm{F}$ & CTCCGCTGGCTAAAGT \\
\hline \multirow[t]{3}{*}{ primers } & qgapdh-R & GGACGGGATGATGTTCT \\
\hline & $\mathrm{q} E G F P-\mathrm{F}$ & CCAGGAGCGCACCATCT \\
\hline & $\mathrm{q} E G F P-\mathrm{R}$ & TGCCGTTCTTCTGCTTGTC \\
\hline
\end{tabular}

${ }^{a}$ The italic characters indicated restriction sites for plasmid construction. 
The PCR products of $v h b$ gene and $p t x \mathrm{D}$ gene were amplified using synthesized plasmid pUCK-vhb and pUC57-ptxD with primers BamH I-vhb-F/Xho I-vhb-R and BamH I-ptxD-F/Xho I separately. The purified PCR products and vector pRSFDuet$y d a \mathrm{O}$ were digested with BamH I and Xho I. The relative fragments were then cloned into plasmid pRSFDuet-ydaO, designated as plasmids pRSFDuet-ydaO-vhb and pRSFDuet-ydaOptxD, respectively.

\section{Analytical procedures}

The cell growth was analyzed by measuring the optical density of the fermentation broth at $600 \mathrm{~nm}$ using a spectrophotometer (Thermo Scientific, USA). SAM was extracted from the culture broth with $10 \%(\mathrm{w} / \mathrm{v})$ perchloric acid for $1 \mathrm{~h}$ at $30^{\circ} \mathrm{C}$. For ATP and ADP determination, the harvested cells were re-suspended in $0.4 \mathrm{~mol} \mathrm{~L}^{-1}$ perchloric acid. Subsequent analysis of SAM and ATP/ADP were all carried out by HPLC according to the previous study. ${ }^{18}$ The fluorescence intensity was measured by flow cytometer (BD, USA).

Isolation of RNA was carried out using total RNA extract kit (Tiangen Biotech, China) and synthesis of cDNA from mRNA was performed using the Quantscript RTFirst Strand cDNA Synthesis Kit (Beijing TransGen Biotech Company, China) according to the manufacturer's instructions. The quantitative real-time PCR (qPCR) was performed on a Rotor-Gene Q system (Analytikjena, Germany) using the Trans Start Top Green qPCR Supermix (Beijing TransGen Biotech Company, China) according to the precious study. ${ }^{21}$ Each qPCR reaction was performed with three biological replicates. The qPCR primers were listed in Table 2.

\section{Results and discussion}

\section{Verification the expression of $y d a O$ motif in $E$. coli}

Flow cytometry and qPCR were performed to determine the fluorescence intensity of the strain AYG which harbors ydaO

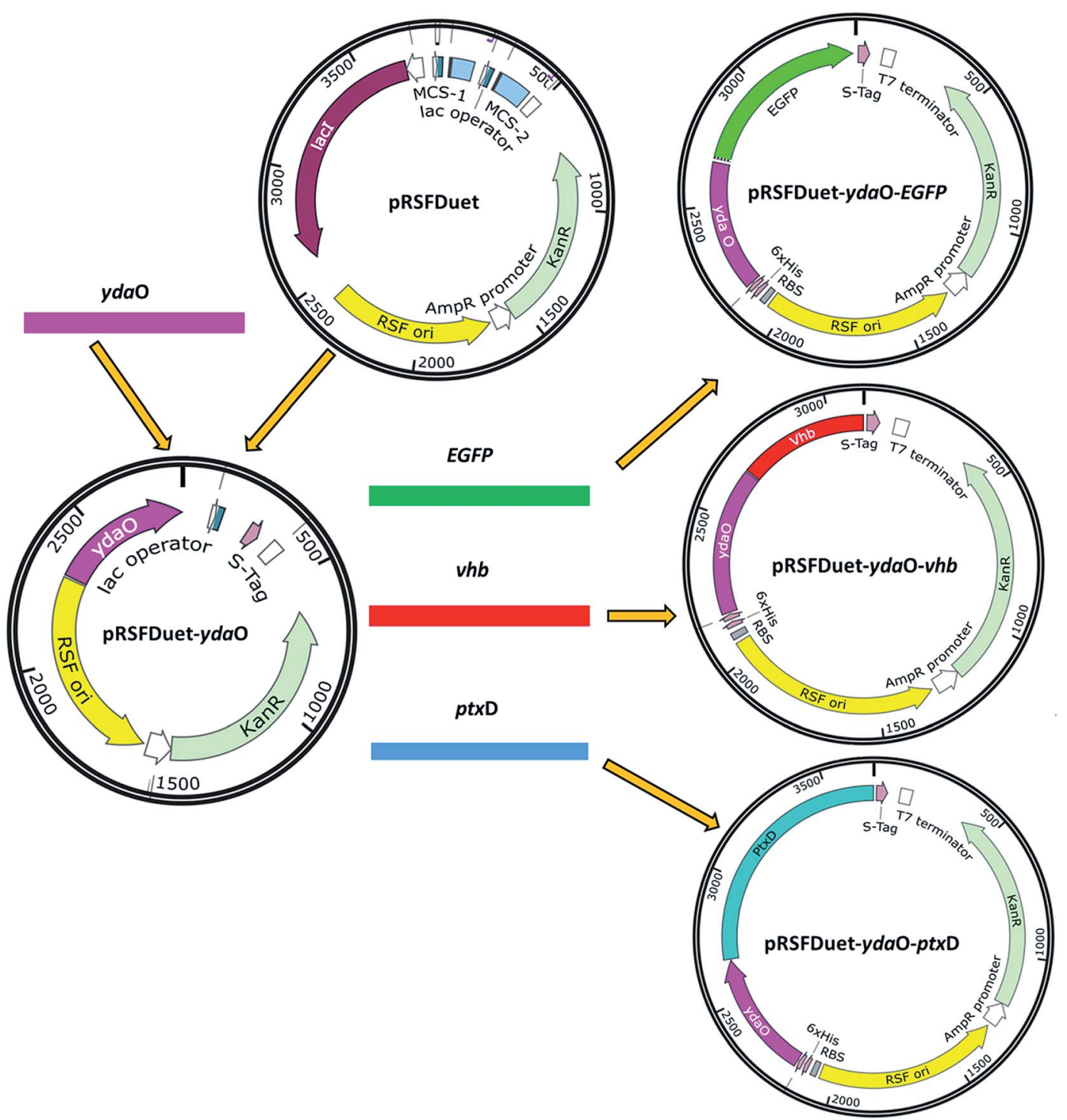

Fig. 2 Schematic overview of the plasmids design and construction. 

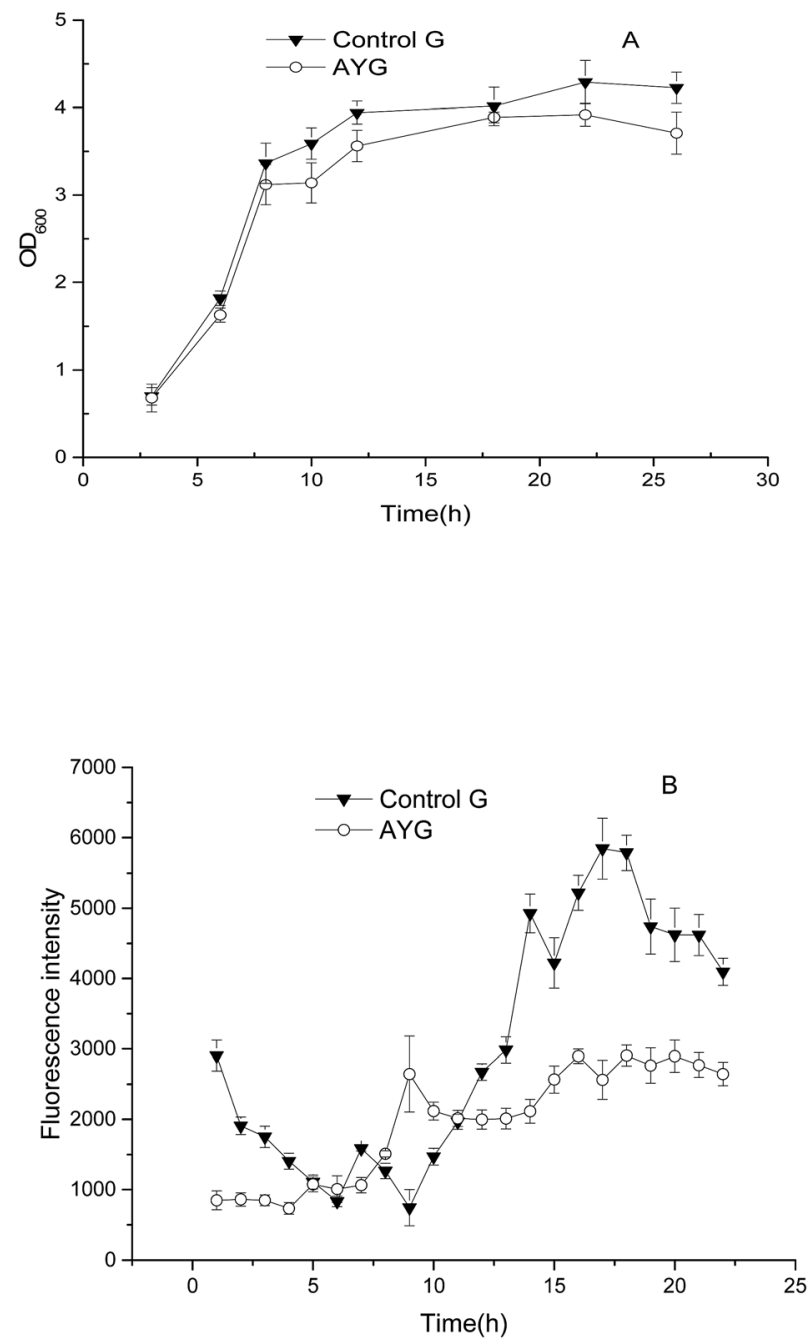

Fig. 3 Comparison of cell growth (A) and fluorescence intensity (B) in the control and the recombinant $E$. coli under different cultivating time.

motif and enhanced green fluorescent protein (EGFP). EGFP without $y d a \mathrm{O}$ fragment was used to construct the strain Control G. As shown in Fig. 3A, the cell growth of the strain Control G was a little higher than the strain AYG. However, the fluorescence intensity of AYG was significantly higher than that of the control strain in the fermentation of $24 \mathrm{~h}$ (Fig. 3B), which indicated that the $y d a \mathrm{O}$ motif could enhance the EGFP transcription in E. coli. On the whole, the fluorescence intensity of control strain maintained a relatively low level at the initial stage of fermentation process, and it increased and stabilized after $12 \mathrm{~h}$ fermentation. However, the changes of fluorescence intensity in the strain AYG differed with the control. Firstly, the fluorescence intensity changed with the fermentation time, which means the $y d a \mathrm{O}$ motif is indeed affected and regulated endogenous gene expression under changes of the intracellular environment. Secondly, it's clearly that the fluorescence intensity of strain AYG increased at first and then decreased in the initial stage of fermentation. Next, the fluorescence intensity increased continuously at the logarithmic phase, the

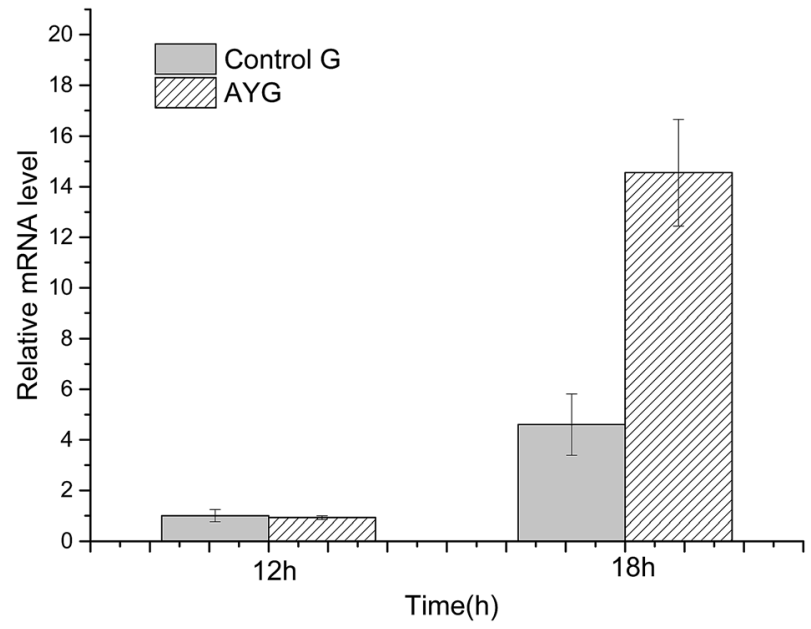

Fig. 4 Comparison of mRNA level in the control and the recombinant E. coli under different cultivating time.

fluorescence intensity decreased to a stable level until the late of stable phase.

The mRNA relative expression level was analyzed by qPCR. The mRNA level of the target genes in all other strains was normalized by reference gene gapdh (encoding glyceraldehyde3-phosphate dehydrogenase) in strain Control G at $12 \mathrm{~h}$, and the normalized mRNA level was assumed to be 1.0. As shown in Fig. 4, the qPCR results clearly indicated that the $y d a \mathrm{O}$ motif from Bacillus subtilis could enhance the gene transcription in $E$. coli.

\section{Effect of regulation of the $y d a O$ motif on the ATP concentration and fluorescence intensity}

The change of fluorescence intensity was due to the effect of $y d a \mathrm{O}$ motif. Actually, the change of intracellular ATP concentration contributed to the disturbance of fluorescence intensity according to the mechanism of riboswitch $y d a \mathrm{O}$. The trends of fluorescence intensity were almost opposite with the level of ATP in AYG strain (Fig. 5). That is, when the ATP level was high,

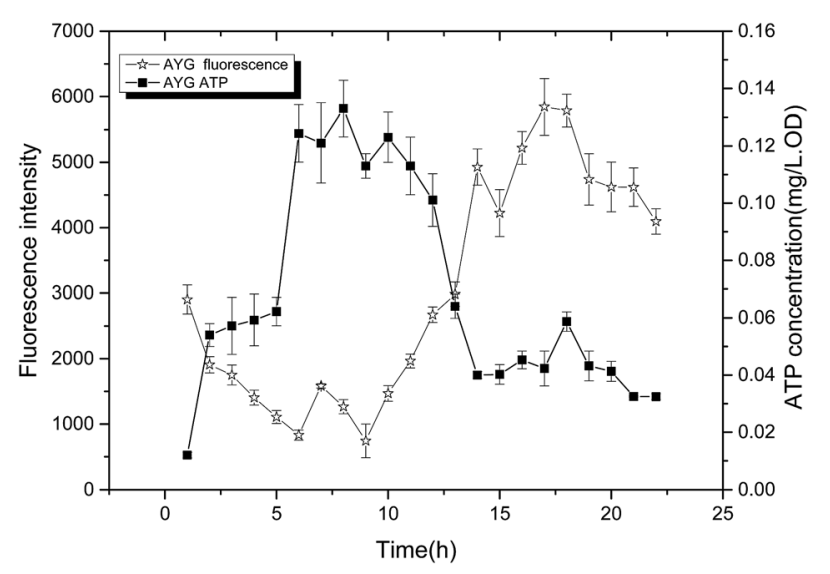

Fig. 5 Comparison of fluorescence intensity and ATP concentration in the strain AYG under different cultivating time. 
the fluorescence intensity was low, and vice versa. It's shown that the intracellular ATP level is lower in the initial stage of fermentation, thus higher fluorescence intensity was observed through driving the transcription of EGFP under regulation of riboswitch $y d a \mathrm{O}$. As the intracellular ATP level reached a higher level gradually during the cell growth, the expression of EGFP was inhibited. The intracellular ATP was consumed to satisfy a large number of metabolic reactions when entering the logarithmic growth phase, thus activating the $y d a \mathrm{O}$ motif to drive the expression of EGFP again. The fluorescence intensity decreased slightly from the death phase, probably due to decline caused by the reduction of $E$. coli. This phenomenon is consistent with the principle that the riboswitch $y d a \mathrm{O}$ motif is in response to intracellular concentration of ATP.

\section{Effect of the ATP sensing riboswitch-based regulation strategy on SAM production}

In our previous work, specific metabolic pathways of byproducts in the SAM metabolic pathway were weakened by
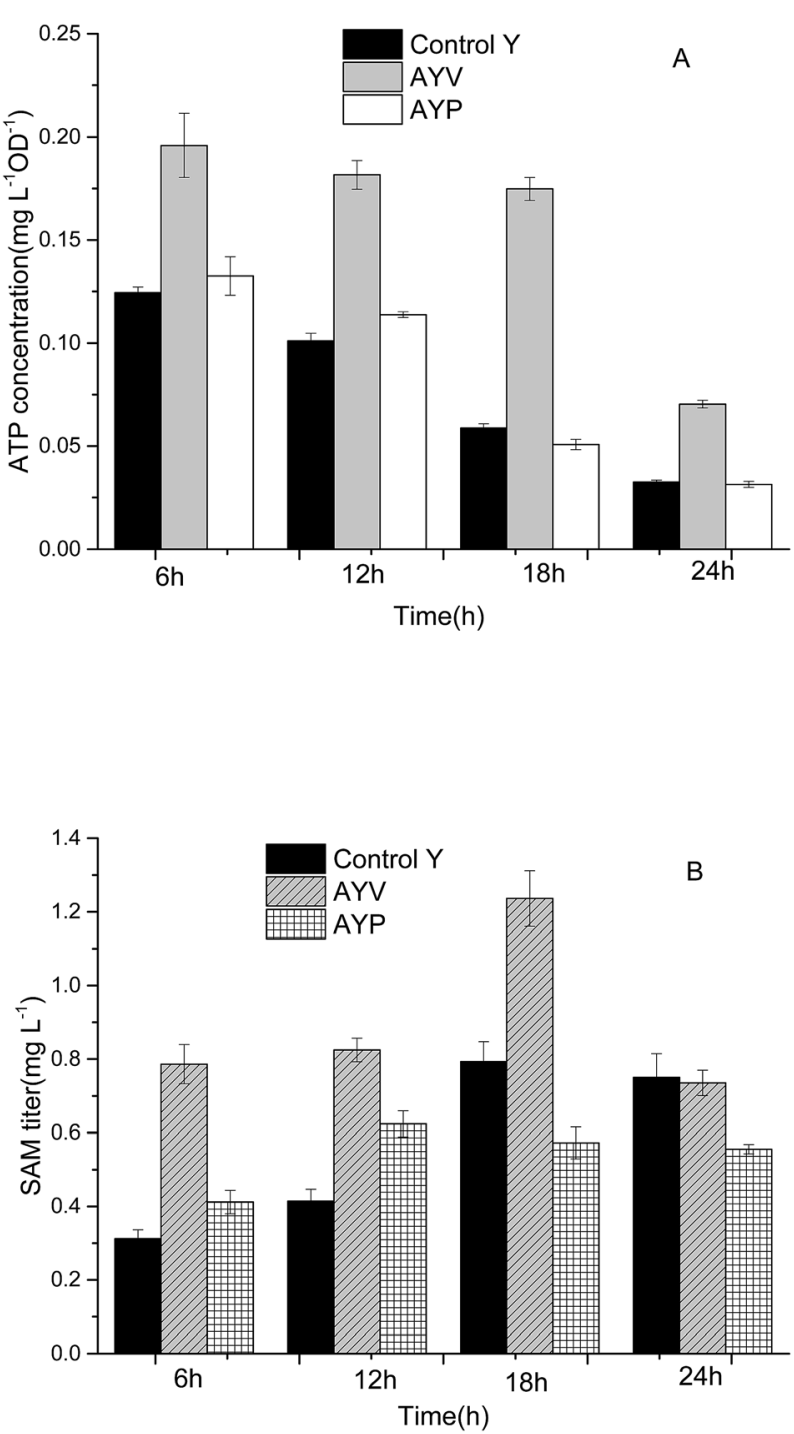

Fig. 6 The effect of ATP dynamic regulation on ATP (A) and SAM (B) titer in flask fermentation of the control and the recombinant $E$. coli. a synthetic sRNA-based regulation strategy. The intracellular ATP level was enhanced and the highest SAM titer could reach to $1.21 \mathrm{mg} \mathrm{L^{-1 }}$ in the best performing strain Anti-argB. ${ }^{18}$ By comparison, the synthetic sRNA-based regulation strategy and the novel method proposed in this study obtained almost the same SAM titer (Fig. 6). However, the regulation of synthetic sRNA-based regulation strategy could only up-regulate or downregulate the intracellular ATP level. The development of ATPsensing riboswitch $y d a \mathrm{O}$ has offered a novel approach to regulate the intracellular ATP level dynamically.

As the most important electron donor in oxidative phosphorylation, increased NADH level could promote the synthesis of ATP effectively. ${ }^{22,23}$ The phosphite dehydrogenase (PTDH) from Pseudomonas stutzeri catalyzes the nearly irreversible oxidation of hydrogen phosphonate (phosphite) to phosphate with the concomitant reduction of $\mathrm{NAD}^{+}$to NADH. ${ }^{24,25}$ Vitreoscilla hemoglobin (VHb) was first studied in the 1960s. VHb could bind oxygen, particularly under low $\mathrm{O}_{2}$ conditions, and deliver it to the respiratory chain by direct interaction with the terminal respiratory cytochrome. ${ }^{26,27}$ In this way, it likely enhances aerobic oxidative phosphorylation when $\mathrm{O}_{2}$ is scarce, thus promoting the synthesis of ATP. The PTDH and VHb were always manipulated to increase the intracellular ATP level recently. ${ }^{28-30}$

As can be seen from Fig. 6, the SAM titer of strain AYP increased at the first $12 \mathrm{~h}$ and then no longer increased or even decreased slightly. The change of SAM titer in AYP was consistent with the change of ATP (Fig. 5). The reason may be due to the $p t x \mathrm{D}$ gene was optimized in $S$. cerevisiae codon, which is not suitable for expression in $E$. coli. In addition, introduction of PTDH changes the ATP level as well as NADH level in vivo. And the SAM tier was not only tightly associated with the ATP level but also affected by NADH level. The change of these cofactors in concentration or form could disturb the intracellular redox balance and energy status, affect the key enzyme in central carbon metabolism and redistribute the metabolites. ${ }^{31}$

Compared with the strain Control Y and strain AYP, the intracellular ATP level of the strain AYV was higher, and was relatively stable during the whole fermentation cycle. It indicated that the $y d a \mathrm{O}$ motif plays a role in intracellular regulation of ATP concentration and maintains the intracellular ATP level at $0.17 \mathrm{mg} \mathrm{L}^{-1} \mathrm{OD}^{-1}$ stably. The intracellular ATP concentration of AYV strain increased by $57 \%, 80 \%, 198 \%$ and $117 \%$, respectively after fermentation for $6 \mathrm{~h}, 12 \mathrm{~h}, 18 \mathrm{~h}, 24 \mathrm{~h}$ comparing with the strain Control Y. In addition, the concentration of intracellular SAM of recombinant strain AYV was also significantly higher than that of the control strain. Especially in the $18 \mathrm{~h}$, the SAM concentration of the AYV strain was increased by about $55 \%$, reaching to $1.23 \mathrm{mg} \mathrm{L}^{-1}$.

Although the $y d a \mathrm{O}$ motif is able to regulate the expression of downstream genes in response to the concentration of ATP, it can't regulate intracellular ATP levels to varying degrees. It can only maintain the intracellular ATP concentration on a certain level according to its own response mechanism. And the experimental results showed that the stable ATP level $(0.17 \mathrm{mg}$ $\mathrm{L}^{-1} \mathrm{OD}^{-1}$ ) obtained by $y d a \mathrm{O}$ regulation is still too low to meet the requirement of SAM synthesis for ATP in E. coli. 


\section{Conclusion}

Control of ATP concentration is critical in the industrial ATPdriven bioprocesses. ${ }^{32}$ We set out to develop such a regulation platform based on the ATP-sensing riboswitch ydaO, which would enable balance of intracellular ATP concentration dynamically. This platform was designed based upon the mechanism that low-level ATP could promote the gene transcription. In developing and testing this platform, we designed a GFP marked recombinant strain in E. coli. The expression of $y d a \mathrm{O}$ from Bacillus subtilis in E. coli was confirmed. And it's also shown that the RNA element $y d a \mathrm{O}$ could play a role in regulating gene expression in $E$. coli. The $y d a \mathrm{O}$ motif, which was induced by ATP, was further applied to regulate ATP concentration. The strategy improved the ATP level as well as the titer of the SAM, which proved that the $y d a \mathrm{O}$ motif had a certain positive effect on the maintenance of intracellular ATP level.

The $y d a \mathrm{O}$ motif-based regulation strategy can be a potential tool to balance ATP level for the production of ATP-driven metabolites. However, there is still room for further research aiming at modifying the $y d a \mathrm{O}$ motif to broaden its response range to satisfy the SAM production. However, ATP regulation can disturb the whole metabolic network, thus combining with metabolomics analysis for improving the SAM production would be a better way. In addition, the codon optimized gene of $p t x \mathrm{D}$ for expression in $E$. coli or other genes related in the ATP synthesis could be applied in the $y d a \mathrm{O}$ motif-based regulation system for a better productivity of ATP-driven products.

\section{Acknowledgements}

This work was supported by the National Nature Science Foundation of China $(21606073,21390202,21436002)$, the National Basic Research Program of China (973 program) (2013CB733600, 2012CB725200) and the National Key Scientific Instruments and Equipment Development Special Fund (2012YQ0401400302).

\section{References}

1 P. Giulidori, M. Galli-Kienle, E. Catto and G. Stramentinoli, J. Biol. Chem., 1984, 259, 4205.

2 S. C. Lu, Int. J. Biochem. Cell Biol., 2000, 32, 391-395.

3 M. A. Grillo and S. Colombatto, Amino Acids, 2008, 34, 187193.

4 S. Gregoire, M. Millecamps, L. Naso, S. D. Carmo, A. C. Cuello, M. Szyf and L. S. Stone, Pain, 2017, 158, 802-810. 5 H. J. H. Blewett, Crit. Rev. Food Sci. Nutr., 2008, 48, 458-463. 6 C. S. Lieber and L. Packer, Am. J. Clin. Nutr., 2002, 76, 1148S$1150 \mathrm{~S}$.

7 Q. M. Anstee and C. P. Day, J. Hepatol., 2012, 57, 1097-1109.
8 D. Mischoulon and M. Fava, Am. J. Clin. Nutr., 2002, 76, 1158S-1161S.

9 G. van der Watt, J. Laugharne and A. Janca, Curr. Opin. Psychiatr., 2008, 21, 37-42.

10 M. Kanai, M. Mizunuma, T. Fujii and H. Iefuji, Appl. Microbiol. Biotechnol., 2017, 101, 1351-1357.

11 S. Shiozaki, S. Shimizu and H. Yamada, Agric. Biol. Chem., 1984, 48, 2293-2300.

12 K. Mincheva, V. Kamburova and V. Balutzov, Biotechnol. Lett., 2002, 24, 1773-1777.

13 J. Zhang, X. Wang, E. Su, G. Fang, Y. Ren and D. Wei, Biochem. Eng. J., 2008, 41, 74-78.

14 W. Zhao, F. Shi, B. Hang, L. Huang, J. Cai and Z. Xu, Appl. Biochem. Biotechnol., 2016, 178, 1263-1272.

15 H. R. Kant, M. Balamurali and S. Meenakshisundaram, J. Biotechnol., 2014, 188, 112-121.

16 M. H. Li, X. M. Meng, E. J. Diao, F. L. Du and X. Y. Zhao, J. Chem. Technol. Biotechnol., 2012, 87, 1379-1384.

17 Y.-A. Na, J.-Y. Lee, W.-J. Bang, H. J. Lee, S.-I. Choi, S.-K. Kwon, K.-H. Jung, J. F. Kim and P. Kim, J. Ind. Microbiol. Biotechnol., 2015, 42, 915-924.

18 Y. Chen, S. Lou, L. Fan, X. Zhang and T. Tan, FEMS Microbiol. Lett., 2015, 362, fnv115.

19 P. Y. Watson and M. J. Fedor, Nat. Chem. Biol., 2012, 8, 963965.

20 A. Serganov and E. Nudler, Cell, 2013, 152, 17-24.

21 M. Wang, L. Hu, L. Fan and T. Tan, Energy Fuels, 2015, 29, 1823-1829.

22 X. Zhu, Z. Tan, H. Xu, J. Chen, J. Tang and X. Zhang, Metab. Eng., 2014, 24, 87-96.

23 J. Y. Lee, C. D. Kang, S. H. Lee, Y. K. Park and K. M. Cho, Biotechnol. Bioeng., 2015, 112, 751-758.

24 J. M. Vrtis, A. K. White, W. W. Metcalf and W. A. van der Donk, J. Am. Chem. Soc., 2001, 123, 2672-2673.

25 R. Woodyer, W. A. van der Donk and H. M. Zhao, Biochemistry, 2003, 42, 11604-11614.

26 B. C. Stark, K. R. Pagilla and K. L. Dikshit, Appl. Microbiol. Biotechnol., 2015, 99, 1627-1636.

27 P. Y. Chi, D. A. Webster and B. C. Stark, Microbiol. Res., 2009, 164, 267-275.

28 S. M. S. Reshamwala, S. K. Pagar, V. S. Velhal, V. M. Maranholakar, V. G. Talangkar and A. M. Lali, J. Biosci. Bioeng., 2014, 118, 628-631.

29 G. Han, X. Hu and X. Wang, Enzyme Microb. Technol., 2015, 78, 27-33.

30 T.-X. Zhao, M. Li, X. Zheng, C.-H. Wang, H.-X. Zhao, C. Zhang and X.-H. Xing, J. Biosci. Bioeng., 2017, 123, 109115.

31 X. L. Chen, S. B. Li and L. M. Liu, Trends Biotechnol., 2014, 32, 337-343.

32 K. Y. Hara and A. Kondo, Microb. Cell Fact., 2015, 14, 9. 